Original Research Paper

\title{
Digestibility of Energy and Crude Protein in Korean Rice Wine Residues Fed to Pigs
}

\author{
${ }^{1}$ Mariette Bessem Akonjuen, ${ }^{1}$ Bokyung Hong, ${ }^{1}$ Hyunjun Choi and ${ }^{1,2}$ Beob Gyun Kim \\ ${ }^{1}$ Department of Animal Science and Technology, Konkuk University, Seoul, Republic of Korea \\ ${ }^{2}$ Monogastric Animal Feed Research Institute, Konkuk University, Seoul, Republic of Korea
}

\author{
Article history \\ Received: 24-06-2019 \\ Revised: 19-08-2019 \\ Accepted: 30-08-2019 \\ Corresponding Author: \\ Beob Gyun Kim \\ Department of Animal Science \\ and Technology, \\ Konkuk University, Seoul, \\ Republic of Korea \\ Email: bgkim@konkuk.ac.kr
}

\begin{abstract}
Two experiments were conducted to determine the digestibility of energy and Crude Protein (CP) in Korean Rice Wine Residues (RWR) using in vitro and in vivo approaches. In the in vitro experiment, 2-step and 3 -step in vitro disappearance procedures were employed to determine in vitro Ileal Disappearance (IVID) and in vitro Total Tract Disappearance (IVTTD) of nutrients, respectively, in corn, a Soybean Meal-Wheat Mixture (SBMW), RWR and the experimental diets used in the in vivo experiment. In the in vivo experiment, 3 Jeju Island native pigs fitted with a T-cannula in the distal ileum with an initial mean body weight of $74.8 \pm 5.4 \mathrm{~kg}$ were individually housed in pens equipped with a feeder and a nipple drinker. A replicated $3 \times 3$ Latin square design was employed with 3 dietary treatments, 6 periods and 3 animals. Three experimental diets based on the corn and SBMW with a constant ratio (corn:SBMW $=3.06: 1$ ) were formulated to contain 0,15 or $30 \%$ of RWR. All diets contained $0.5 \%$ chromic oxide as an indigestible index. Korean RWR had greater IVID of Dry Matter $(\mathrm{DM})$ than corn and SBMW $(\mathrm{p}<0.05)$. The IVID of CP in RWR was less than that of corn and SBMW $(p<0.05)$. The IVTTD of DM in RWR was greater than that of corn but less than that of SBMW $(p<0.05)$. The IVID of CP linearly decreased as the inclusion rate of RWR increased $(p<0.001)$. The digestible energy concentration $(\mathrm{kcal} / \mathrm{kg} \mathrm{DM})$ in diets increased linearly with an increase in RWR in the diets $(\mathrm{p}=0.001)$. The apparent and standardized ileal digestibility of CP in the diets showed a linear decrease $(p<0.001)$ as the inclusion rate of RWR increased. In conclusion, Korean rice wine residues have a high digestible energy concentration and may be used in swine diets with attention to protein utilization.
\end{abstract}

Keywords: Digestible Energy, Makgeolli By-Product, Pigs, Rice Wine Residues

\section{Introduction}

The use of by-products for livestock feeding has increased over the last few decades due to the fluctuations in the price of conventional feed ingredients. When using the by-products in animal feeds, the knowledge of energy and nutrient availability in the byproduct feed ingredients is crucial (Rijal et al., 2009; NRC, 2012). Accordingly, a number of data have been reported to provide biological availability of energy and nutrients (Son et al., 2014; Casas et al., 2015; 2018; Sung et al., 2019).

Korean Rice Wine Residues (RWR) called "Makgeolli by-products" are the residues after the fermentation of rice to produce wine. The RWR have been studied as an ingredient for cattle feeds (Piao et al., 2012; Jeong et al., 2016). To our knowledge, however, there is no information on the nutritional values of RWR as an ingredient for swine diets.

While animal experiments are often used for determining the digestibility of energy and nutrients in feedstuffs, animal experimentation is expensive and time-consuming. As an alternative method, in vitro procedures are available for routine determination of the digestibility of energy (Boisen and Fernández, 1997) and protein (Boisen and Fernández, 1995) in swine feedstuffs. Therefore, the objective of this study was to determine the Digestible Energy (DE) and digestibility of Crude Protein (CP) in Korean RWR fed to pigs using in vitro and in vivo approaches. 


\section{Materials and Methods}

The protocol for the experiment was approved by the Institutional Animal Care and Use Committee at Konkuk University (KU18126).

\section{Preparation of Korean Rice Wine Residues}

Korean RWR from a Korean traditional wine (Makgeolli) processing company were dried in a forcedair drying oven at $55^{\circ} \mathrm{C}$ for 4 days to contain $15.9 \%$ moisture (Table 1).

\section{In Vitro Ileal Disappearance Experiment}

The in vitro Ileal Disappearance (IVID) of Dry Matter (DM) and CP were determined using a 2-step in vitro digestibility procedure described by Boisen and Fernández (1995) with minor modifications.

One $\mathrm{g}$ of a ground (1-mm sieve) ingredient or a diet sample was transferred into $100-\mathrm{mL}$ conical flasks. A 25 $\mathrm{mL}$ of sodium phosphate buffer solution $(0.1 \mathrm{M}, \mathrm{pH} 6.0)$ and $10 \mathrm{~mL}$ of $\mathrm{HCl}(0.2 \mathrm{M}, \mathrm{pH} 0.7)$ were added to the sample. To simulate digestion conditions in the stomach, $1 \mathrm{M} \mathrm{HCl}$ or $\mathrm{NaOH}$ was used to adjust the $\mathrm{pH}$ to 2.0 and $1 \mathrm{~mL}$ of freshly prepared pepsin solution (10 $\mathrm{mg} / \mathrm{mL} ; \geq 250$ units/mg solid, P7000, pepsin from porcine gastric mucosa, Sigma-Aldrich, St. Louis, MO, USA) was added to the samples. To avoid bacterial contamination, $0.5 \mathrm{~mL}$ of chloramphenicol (C0378, Chloramphenicol, Sigma-Aldrich, St. Louis, MO, USA) solution ( $5 \mathrm{~g} / \mathrm{L}$ ethanol) was also added. Test flasks were closed with a silicon stopper and incubated in a shaking incubator at $39^{\circ} \mathrm{C}$ for $6 \mathrm{~h}$.

After incubation, the second step of the procedure simulated the digestion in the small intestine. Firstly, 10 $\mathrm{mL}$ of sodium phosphate buffer solution $(0.2 \mathrm{M}, \mathrm{pH} 6.8)$ and $5 \mathrm{~mL}$ of $\mathrm{NaOH}(0.6 \mathrm{M}, \mathrm{pH} 13.8)$ were added to the samples. Then, the $\mathrm{pH}$ was adjusted to 6.8 using $1 \mathrm{M}$ $\mathrm{HCl}$ or $\mathrm{NaOH}$. Thereafter, $1 \mathrm{~mL}$ of freshly prepared pancreatin solution $(50 \mathrm{mg} / \mathrm{mL} ; 4 \times \mathrm{USP}, \mathrm{P} 1750$, pancreatin from porcine pancreas, Sigma-Aldrich, St. Louis, MO, USA) was added. After incubation in a shaking incubator at $39^{\circ} \mathrm{C}$ for $18 \mathrm{~h}, 5 \mathrm{~mL}$ of $20 \%$ sulfosalicylic acid solution was added and samples were left for $30 \mathrm{~min}$ at room temperature to precipitate the indigestible protein. The samples were then filtered through pre-dried and pre-weighed glass filter crucibles (Filter Crucibles CFE Por. 2, Robu, Hattert, Germany) containing $400 \mathrm{mg}$ of celite using the Fibertec System (Fibertec System 1021 Cold Extractor, Tecator, Höganäs, Sweden). Test flasks were rinsed twice with $1 \%$ sulfosalicylic acid solution and $10 \mathrm{~mL}$ of $95 \%$ ethanol and $99.5 \%$ acetone were added twice to the glass filter crucibles. Glass filter crucibles with undigested residues were dried at $80^{\circ} \mathrm{C}$ for $24 \mathrm{~h}$. The undigested materials together with the celite were wrapped into a piece of nitrogen-free paper and kept for further analysis.
Table 1: Analyzed nutrient composition of corn, Soybean Meal-Wheat Mixture (SBMW) and Rice Wine Residues (RWR), as-fed basis

\begin{tabular}{llll}
\hline Item & Corn & SBMW $^{1}$ & RWR \\
\hline Dry matter, \% & 86.40 & 89.02 & 84.10 \\
Gross energy, kcal/kg & 3,737 & 4,105 & 3,977 \\
Crude protein, \% & 8.57 & 38.00 & 15.30 \\
Ash, \% & 1.70 & 5.93 & 0.53 \\
Neutral detergent fiber, \% & 8.33 & 5.55 & 4.18 \\
Acid detergent fiber, \% & 2.56 & 3.29 & 2.54 \\
\hline${ }^{1}$ The ratio of soybean meal and wheat was 65.35 in the mixture
\end{tabular}

\section{In Vitro Total Tract Disappearance Experiment}

The in vitro Total Tract Disappearance (IVTTD) of $\mathrm{DM}$ and $\mathrm{CP}$ was determined using 3-step in vitro digestibility techniques described by Boisen and Fernández (1997) with minor modifications.

The first and second steps were similar to the IVID procedure, except for the weight of the samples, the concentration of the enzymes and incubation time. For IVTTD, $0.5 \mathrm{~g}$ of each ingredient sample was used and the concentrations of pepsin and pancreatin solutions were increased to 25 and $100 \mathrm{mg} / \mathrm{mL}$, while the incubation periods were reduced to 2 and $4 \mathrm{~h}$, respectively. In the third step of the IVTTD procedure, $10 \mathrm{~mL}$ of $0.2 \mathrm{M}$ EDTA solution was added to the samples. The $\mathrm{pH}$ was then adjusted to 4.8 by adding acetic acid $30 \%$ or $1 \mathrm{M}$ $\mathrm{NaOH}$. Samples were supplemented with $0.5 \mathrm{~mL}$ of multi-enzyme (V2010, Viscozyme ${ }^{\circledR}$, Sigma-Aldrich, St. Louis, MO, USA) as a substitute for microbial enzymes and incubated in a shaking incubator for $18 \mathrm{~h}$ at $39^{\circ} \mathrm{C}$. After incubation, the undigested residues were collected and dried as previously described in the IVID procedure except for the drying condition (at $130^{\circ} \mathrm{C}$ for $6 \mathrm{~h}$ ) and kept for further analysis.

\section{In Vivo Digestibility Experiment}

Three Jeju Island native pigs fitted with a T-cannula in the distal ileum with an initial mean Body Weight (BW) of $74.8 \pm 5.4 \mathrm{~kg}$ were individually housed in pens equipped with a feeder and a nipple drinker. The pigs were surgically fitted with a T-cannula in the distal ileum using the procedures adapted from Stein et al. (1998). A replicated $3 \times 3$ Latin square design was employed with 3 dietary treatments, 6 periods and 3 animals. The amount of daily feed intake was calculated at approximately 1.5 times the estimated energy requirement for maintenance (i.e., $197 \mathrm{kcal}$ of metabolizable energy per $\mathrm{kg}$ of $\mathrm{BW}^{0.60}$; $\left.\mathrm{NRC}, 2012\right)$ and divided into 2 equal meals and fed to pigs at 0800 and $1700 \mathrm{~h}$. Water was available at all times. The basal diet contained mainly corn and a Soybean Meal-Wheat Mixture (SBMW) at the ratio of 65:35 while the other 2 additional diets were formulated to contain 15 or $30 \%$ of RWR at the expense of corn and SBMW with a constant ratio (3.06:1) of corn:SBMW (Table 2). 
Vitamins and minerals were included in all diets to meet or exceed requirement estimates for growing pigs (NRC, 2012). All diets contained $0.5 \%$ chromic oxide $\left(\mathrm{Cr}_{2} \mathrm{O}_{3}\right)$ as an indigestible index.

An experimental period consisted of a 7-d adaptation and a 4-d collection periods composed of $2 \mathrm{~d}$ of fecal collection followed by $2 \mathrm{~d}$ of ileal digesta collection. Fecal samples were collected by the grab sampling procedure for the index method (Kong and Adeola, 2014). The ileal digesta samples were collected from 0800 to $1700 \mathrm{~h}$. A plastic sample bag with wire was fixed to the T-cannula for the ileal digesta collection. A sample bag was changed at least once every $30 \mathrm{~min}$, or whenever the bag was filled with ileal digesta. The collected ileal digesta samples for each animal were pooled together and then subsampled. These samples were immediately stored at $-20^{\circ} \mathrm{C}$. At the end of each period, BW was measured to determine the amount of feed allowance during the next period.

\section{Chemical Analysis}

The undigested residues from the 2-step in vitro experiment were analyzed for CP (AOAC, 2005; method 990.03) for the calculation of IVID of CP. The fecal samples were dried in a forced-air drying oven at $55^{\circ} \mathrm{C}$ and ground before analysis. The frozen ileal digesta samples were dried in a freeze dryer. Ingredients, diets, fecal and ileal digesta samples from the in vivo experiment were analyzed for Gross Energy (GE) using a bomb calorimeter (Parr 1261 bomb calorimeter; Parr Instruments Co., Moline, IL, USA) and analyzed for DM (AOAC, 2005; method 930.15) and CP. Samples of ingredients and diets were also analyzed for ash (AOAC, 2005; method 942.05), Neutral Detergent Fiber (NDF; Van Soest et al., 1991) and Acid Detergent Fiber (ADF; AOAC, 2005; method 973.18). Chromium (Cr) concentrations of the diet, feces and ileal digesta samples were analyzed by using spectrophotometer (Optizen 2120UV, Mecasys Inc., Daejeon, Republic of Korea).

\section{Calculations and Statistical Analysis}

The IVID or IVTTD of DM (\%) was calculated using the following equation (Kong et al., 2015):

$$
\begin{aligned}
& \text { IVID or IVTTD of DM }(\%) \\
& =\left[\left(D M_{T I}-D M_{R S}\right) \div D M_{T I}\right] \times 100
\end{aligned}
$$

where, $D M_{T I}$ and $D M_{R S}(\mathrm{~g})$ are the weight of $D M$ in the test ingredient and the undigested residues, respectively, collected from IVID or IVTTD procedure. The IVID of $\mathrm{CP}$ was also calculated using the same equation.

The Apparent Total Tract Digestibility (ATTD) of GE was calculated based on the GE and $\mathrm{Cr}$ concentrations in feces and diet. The DE concentration of diets was calculated by multiplying ATTD of GE to
GE in diets. The Apparent Ileal Digestibility (AID) and Standardized Ileal Digestibility (SID) of CP were calculated based on $\mathrm{CP}$ and $\mathrm{Cr}$ concentrations of the diet and ileal digesta (Stein et al., 2007; Kong and Adeola, 2014). Values for the ATTD of GE and AID and SID of $\mathrm{CP}$ were calculated according to the following equations (Son et al., 2014):

$$
\begin{gathered}
\text { ATTD of } G E(\%) \\
=\left[1-\left(G E_{\text {feces }} \div G E_{\text {diet }}\right) \times\left(C r_{\text {diet }} \div C r_{\text {feces }}\right)\right] \times 100 \\
\text { AID of } C P(\%) \\
=\left[1-\left(C P_{\text {ileal }} \div C P_{\text {diet }}\right) \times\left(C r_{\text {diet }} \div C r_{\text {ileal }}\right)\right] \times 100 \\
\text { SID of } C P(\%) \\
=\text { AID of } C P+\left[\left(B E L \text { of } C P \div C P_{\text {diet }}\right) \times 100\right]
\end{gathered}
$$

where, $G E_{\text {feces }}$ is GE concentration in the feces $(\mathrm{kcal} / \mathrm{kg}$ of DM), $G E_{\text {diet }}$ is GE concentration in the $\operatorname{diet}(\mathrm{kcal} / \mathrm{kg}$ of $\mathrm{DM}), C P_{\text {ileal }}$ is the concentration of $\mathrm{CP}$ in the ileal digesta, $C P_{\text {diet }}$ is the concentration of $\mathrm{CP}$ in the diet, $C r_{\text {diet }}$ is the concentration of $\mathrm{Cr}$ in the diet and $C r_{\text {ileal }}$ is the concentration of $\mathrm{Cr}$ in the ileal digesta. The $\mathrm{CP}$ and $\mathrm{Cr}$ concentrations were expressed as $\mathrm{g} / \mathrm{kg}$ of DM. The Basal Endogenous Losses (BEL) of CP were assumed to be $17.2 \mathrm{~g} / \mathrm{kg}$ of DM intake (Park et al., 2013).

Data were analyzed by the MIXED procedure of SAS (SAS Inst. Inc., Cary, NC, USA). The model included dietary treatment as fixed variable and animal and period as random variables. Differences between least squares means were determined by the PDIFF option with the Tukey's adjustment. Preplanned orthogonal contrasts were used to evaluate linear and quadratic effect of dietary inclusion rate of RWR. The experimental unit was a flask in in vitro experiment and a pig in in vivo experiment and the statistical significance was set at $\mathrm{p}<0.05$.

\section{Results}

Korean RWR contain greater GE and CP compared with corn but less values than SBMW (Table 1). Moreover, RWR had the lowest values for ash and NDF concentrations. Analyzed diet nutrient concentrations were generally in agreement with the calculated values (Table 2).

\section{In Vitro Disappearance Experiment}

Korean RWR had greater IVID of DM $(p<0.05)$ than corn or SBMW (Table 3). However, the IVID of CP in RWR was less than that of corn and SBMW $(p<0.05)$. The IVTTD of DM in RWR was greater $(p<0.05)$ than that of corn but less than that of SBMW.

The IVID of DM showed a quadratic response ranging from 84.9 to $85.7 \%$ as the inclusion rate of RWR increased $(p=0.024$; Table 4). The IVID of CP decreased linearly as the inclusion rate of RWR increased $(p<0.001)$. 
Table 2: Ingredient composition of experimental diets, as-fed basis

\begin{tabular}{|c|c|c|c|}
\hline \multirow[b]{2}{*}{ Item } & \multicolumn{3}{|l|}{ Diet } \\
\hline & Basal diet & $15 \%$ RWR & $30 \%$ RWR \\
\hline \multicolumn{4}{|l|}{ Ingredient, \% } \\
\hline Ground corn & 73.40 & 62.13 & 50.83 \\
\hline Soybean meal-wheat mixture $^{1}$ & 24.00 & 20.32 & 16.62 \\
\hline Rice Wine Residues (RWR) & - & 15.00 & 30.00 \\
\hline Limestone & 0.70 & 0.60 & 0.45 \\
\hline Dicalcium phosphate & 0.80 & 0.85 & 1.00 \\
\hline Sodium chloride & 0.30 & 0.30 & 0.30 \\
\hline Vitamin-trace mineral premix ${ }^{2}$ & 0.30 & 0.30 & 0.30 \\
\hline Chromic oxide & 0.50 & 0.50 & 0.50 \\
\hline \multicolumn{4}{|l|}{ Nutrient composition } \\
\hline Dry matter, \% & 87.68 & 87.19 & 86.65 \\
\hline Gross energy, $\mathrm{kcal} / \mathrm{kg}$ & 3,874 & 3,894 & 3,921 \\
\hline Crude protein, $\%$ & 15.45 & 15.55 & 15.75 \\
\hline Ash, \% & 4.80 & 4.55 & 4.12 \\
\hline Neutral detergent fiber, $\%$ & 8.08 & 6.64 & 6.31 \\
\hline Acid detergent fiber, $\%$ & 3.26 & 2.60 & 2.63 \\
\hline
\end{tabular}

${ }^{1}$ The ratio of soybean meal and wheat was $65: 35$ in the mixture

${ }^{2}$ Provided the following quantities per kg of complete diet: vitamin A, 6,000 IU; vitamin $\mathrm{D}_{3}, 1,200 \mathrm{IU}$; vitamin $\mathrm{E}, 0.75 \mathrm{IU}$; vitamin $\mathrm{K}$, 0.3 $\mathrm{mg}$; thiamin, $0.29 \mathrm{mg}$; riboflavin, $0.9 \mathrm{mg}$; pyridoxine, $0.6 \mathrm{mg}$; vitamin $\mathrm{B}_{12}, 3.6 \mu \mathrm{g}$; pantothenic acid, $3.0 \mathrm{mg}$; folic acid, $0.6 \mathrm{mg}$; niacin, 6.0 $\mathrm{mg}$; biotin, $0.06 \mathrm{mg}$; $\mathrm{Cu}, 1.5 \mathrm{mg}$ as copper sulfate; $\mathrm{Fe}, 12 \mathrm{mg}$ as iron sulfate; I, $0.75 \mathrm{mg}$ as calcium iodate; $\mathrm{Mn}, 36 \mathrm{mg}$ as manganese sulfate; $\mathrm{Zn}, 45 \mathrm{mg}$ as zinc sulfate; $\mathrm{Co}, 0.3 \mathrm{mg}$ as cobaltous carbonate; $\mathrm{Mg}, 6.0 \mathrm{mg}$ as magnesium oxide; and choline chloride, $75 \mathrm{mg}$

Table 3: In vitro Ileal Disappearance (IVID) of Dry Matter (DM), IVID of Crude Protein (CP) and in vitro Total Tract Disappearance (IVTTD) of DM in corn, a Soybean Meal-Wheat Mixture (SBMW) and Rice Wine Residues (RWR) ${ }^{1}$

\begin{tabular}{lllll}
\hline Item, $\%$ & Corn & SBMW $^{2}$ & RWR & SEM $^{3}$ \\
\hline IVID of DM & $85.8^{\mathrm{b}}$ & $82.5^{\mathrm{c}}$ & $89.9^{\mathrm{a}}$ & 0.3 \\
IVID of CP & $77.7^{\mathrm{b}}$ & $91.1^{\mathrm{a}}$ & $73.2^{\mathrm{c}}$ & $<0.001$ \\
IVTTD of DM & $88.8^{\mathrm{c}}$ & $95.6^{\mathrm{a}}$ & $93.6^{\mathrm{b}}$ & $<.5$ \\
\hline
\end{tabular}

${ }^{\mathrm{a}-\mathrm{c}}$ Least squares means within a row without a common superscript $\operatorname{differ}(\mathrm{p}<0.05)$

${ }^{1}$ Each least squares mean represents 3 observations

${ }^{2}$ The ratio of soybean meal and wheat was 65:35 in the mixture

${ }^{3} \mathrm{SEM}=$ standard error of the mean

\section{In Vivo Experiment}

All pigs remained healthy throughout the experiment and consumed all of their designated diets. The DE concentration $(\mathrm{kcal} / \mathrm{kg} \mathrm{DM})$ in diets increased linearly with an increase in RWR in the diets (Table 5; $\mathrm{p}=$ 0.001). As the concentration of RWR increased in the diet, the AID and SID of $\mathrm{CP}$ in the diets linearly decreased $(p<0.001)$.

\section{Discussion}

The CP, ash, NDF and ADF concentrations in RWR used (Table 1) in the present work were less than the values reported by Piao et al. (2012). These differences are likely due to the differences in the processing, fermentation techniques and the additives included during the rice wine production procedure.

The IVID and IVTTD of DM in corn (Table 3) were consistent with the previous studies (Kong et al., 2015; Park et al., 2016). However, the IVID of DM in SBMW was slightly greater than the reported value (Navarro et al.,
2018) while the IVID of CP and IVTTD of DM in SBMW were close to the reported values (Boisen and Fernández, 1995; Navarro et al., 2018). The nutrient concentrations in Soybean Meal (SBM) are often variable (Douglas et al., 2000) depending on the genotype (Palacios et al., 2004) and the growing environment (van Kempen et al., 2002). Heat processing may also affect the nutrient concentrations and bioavailability of nutrients in SBM (Goebel and Stein, 2011). Therefore, the discrepancy in IVID of nutrients of SBM among the studies may be at least partially due to different growing and production conditions of each SBM.

Rice, which is the major cereal in the production of rice wine, contains about $75 \%$ of carbohydrates as starch (NRC, 2012). Starch is highly digestible at the small intestine (Bach Knudsen, 1997), which explains the high IVID of DM in RWR (Table 3) in the present work.

A greater value of IVTTD of DM compared with the IVID of DM is in consistent with the previous studies (Kong et al., 2015; Navarro et al., 2018). In step 3 of in vitro disappearance procedure, multi-enzyme complex $\left(\right.$ Viscozyme $^{\circledR}$ ) containing various NSP-degrading enzymes was used for the digestion of large intestine. 
Table 4: In vitro Ileal Disappearance (IVID) of Dry Matter (DM), IVID of Crude Protein (CP) digestibility and in vitro Total Tract Disappearance (IVTTD) of DM of diets used in the in vivo experiment ${ }^{1}$

\begin{tabular}{|c|c|c|c|c|c|c|}
\hline \multirow[b]{2}{*}{ Item, $\%$} & \multicolumn{4}{|c|}{ Rice wine residues, $\%$} & \multicolumn{2}{|l|}{ p-value } \\
\hline & 0 & 15 & 30 & $\mathrm{SEM}^{2}$ & Linear & Quadratic \\
\hline IVID of DM & 84.9 & 86.7 & 85.7 & 0.4 & 0.194 & 0.024 \\
\hline IVID of CP & 86.0 & 83.0 & 77.1 & 0.5 & $<0.001$ & 0.068 \\
\hline IVTTD of DM & 91.1 & 91.7 & 91.8 & 0.5 & 0.341 & 0.695 \\
\hline
\end{tabular}

${ }^{1}$ Each least squares mean represents 3 observations except for IVID of CP in diet containing $30 \%$ rice wine residues ( 2 observations)

${ }^{2} \mathrm{SEM}=$ standard error of the mean

Table 5: Digestible Energy to Gross Energy ratio (DE:GE), Digestible Energy (DE), Apparent Ileal Digestibility (AID) of Crude Protein (CP) and Standardized Ileal Digestibility (SID) of CP of experimental diets containing graded rice wine residues fed to pigs ${ }^{1}$

\begin{tabular}{|c|c|c|c|c|c|c|}
\hline \multirow[b]{2}{*}{ Item } & \multicolumn{4}{|c|}{ Rice wine residues, $\%$} & \multicolumn{2}{|l|}{ p-value } \\
\hline & 0 & 15 & 30 & $\mathrm{SEM}^{2}$ & Linear & Quadratic \\
\hline DE:GE & 0.90 & 0.90 & 0.89 & 0.01 & 0.238 & 0.055 \\
\hline $\mathrm{DE}^{3}, \mathrm{kcal} / \mathrm{kg}$ & 3,959 & 4,025 & 4,039 & 25 & 0.001 & 0.119 \\
\hline AID of CP, $\%$ & 71.3 & 63.4 & 56.3 & 2.0 & $<0.001$ & 0.852 \\
\hline SID of CP, $\%$ & 81.0 & 73.0 & 65.8 & 2.0 & $<0.001$ & 0.866 \\
\hline
\end{tabular}

${ }^{1}$ Each least square mean represents 6 observations

${ }^{2} \mathrm{SEM}=$ standard error of the mean

${ }^{3}$ Diet DE concentration is expressed in a dry matter basis

Therefore, IVTTD of DM was greater than IVID of DM (Table 4) in the current experiment due to the additional digestion process which simulates the hindgut fermentation. Moreover, greater IVTTD of DM in SBMW than in RWR may be due to the greater fiber concentration in SBMW than that in RWR.

Energy digestibility is highly correlated with the IVTTD of DM (Park et al., 2013; Son et al., 2017). In the present study, neither linear nor quadratic effect of RWR inclusion rate was observed in both of IVTTD of DM and DE:GE (Tables 4 and 5), indicating the consistency among the previous studies and the present study.

While the DE of most diets fed to pigs varies ranging from 70 to $90 \%$ of GE in the diet (Sauvant et al., 2004), the 3 experimental diets in the present work had very comparable DE:GE (Table 5). Thus, the linear effect of the RWR inclusion rate on $\mathrm{DE}(\mathrm{kcal} / \mathrm{kg} \mathrm{DM})$ is most likely due to the GE concentrations in the experimental diets (Table 2). In addition, dietary fiber is also a reason for variation in DE values among diets (Noblet and van Milgen, 2004) as the studies showed that the energy digestibility decreases with increasing dietary fiber concentrations (Le Goff and Noblet, 2001). In the present work, however, the fiber contents in the diets do not appear to be sufficiently variable to cause deviations in energy digestibility.

In the present work, the IVID of $\mathrm{CP}$ and ileal digestibility of CP linearly decreased with increasing RWR inclusion rate which primarily indicates low ileal digestibility of CP in RWR. Additionally, RWR may have potentially lowered ileal $\mathrm{CP}$ digestibility of corn and SBMW in the experimental diets. The low ileal CP digestibility in RWR is likely due to the relatively long drying period (4 days) in this work. The original RWR were wet and thus, had sufficient moisture and sugar to undergo Maillard reactions at a high temperature during drying process (Nursten, 2005; Kim et al., 2012; Ahn et al., 2014). Development of brown color is an indication of the formation of advanced Maillard products (Nursten, 2005; Kim et al., 2012). In the present study, a brown color was observed in RWR after oven-dried at $55^{\circ} \mathrm{C}$ for 4 days. Therefore, the low protein ileal digestibility in RWR is likely due to the Maillard reactions. Further research is warranted to improve protein digestibility in RWR.

\section{Conclusion}

Korean rice wine residues have a quite high digestible energy concentration and may be used in swine diets with attention to protein utilization.

\section{Author's Contributions}

Mariette Bessem Akonjuen: Conducted the animal experiment and drafted most of the manuscript.

Bokyung Hong: Assisted animal care, performed statistical analysis and critically revised statistical and discussion parts of the manuscript.

Hyunjun Choi: Designed the animal experiment, involved in vitro experiments and critically reviewed the manuscript.

Beob Gyun Kim: Supervised the experimental work and manuscript preparation and revised the manuscript. 


\section{Ethics}

This article is original and contains unpublished material. The corresponding author confirms that all of the other authors have read and approved the manuscript and no ethical issues involved.

\section{References}

Ahn, J.Y., D.Y. Kil, C. Kong and B.G. Kim, 2014. Comparison of oven-drying methods for determination of moisture content in feed ingredients. Asian-Australas. J. Anim. Sci., 27: 1615-1622. DOI: 10.5713 /ajas.2014.14305

AOAC, 2005. Official methods of analysis of AOAC International. 18th ed. Assoc. Off. Anal. Chem., Gaithersburg, MD, USA.

Bach Knudsen, K.E., 1997. Carbohydrate and lignin contents of plant materials used in animal feeding. Anim. Feed Sci. Technol., 67: 319-338. DOI: 10.1016/S0377-8401(97)00009-6

Boisen, S. and J.A. Fernández, 1995. Prediction of the apparent ileal digestibility of protein and amino acids in feedstuffs and feed mixtures for pigs by in vitro analyses. Anim. Feed Sci. Technol., 51: 29-43. DOI: 10.1016/0377-8401(94)00686-4

Boisen, S. and J.A. Fernández, 1997. Prediction of the total tract digestibility of energy in feedstuffs and pig diets by in vitro analyses. Anim. Feed Sci. Technol., 68: 277-286. DOI: 10.1016/S0377-8401(97)00058-8

Casas, G.A., J.A.S. Almeida and H.H. Stein, 2015. Amino acid digestibility in rice co-products fed to growing pigs. Anim. Feed Sci. Technol., 207: 150-158. DOI: $10.1016 /$ j. anifeedsci.2015.05.024

Casas, G.A., N.W. Jaworski, J.K. Htoo and H.H. Stein, 2018. Ileal digestibility of amino acids in selected feed ingredients fed to young growing pigs. J. Anim. Sci., 96: 2361-2370. DOI: 10.1093/jas/sky114

Douglas, M.W., C.M. Parsons and M.R. Bedford, 2000. Effect of various soybean meal sources and Avizyme on chick growth performance and ileal digestible energy. J. Appl. Poult. Res., 9: 74-80. DOI: $10.1093 /$ japr/9.1.74

Goebel, K.P. and H.H. Stein, 2011. Ileal digestibility of amino acids in conventional and low-Kunitz soybean products fed to weanling pig. AsianAustralas. J. Anim. Sci., 24: 88-95.

DOI: 10.5713/ajas.2011.90583

Jeong, C.D., L.L. Mamuad, J.Y. Ko, H.G. Sung and K.K. Park et al., 2016. Rumen fermentation and performance of Hanwoo steers fed total mixed ration with Korean rice wine residue. J. Anim. Sci. Technol., 58: 4. DOI: 10.1186/s40781-016-0084-6
Kim, B.G., D.Y. Kil, Y. Zhang and H.H. Stein, 2012. Concentrations of analyzed or reactive lysine, but not crude protein, may predict the concentration of digestible lysine in distillers dried grains with solubles fed to pigs. J. Anim. Sci., 90: 3798-3808. DOI: $10.2527 /$ jas2011-4692

Kong, C. and O. Adeola, 2014. Evaluation of amino acid and energy utilization in feedstuff for swine and poultry diets. Asian-Australas. J. Anim. Sci., 27: 917-925. DOI: 10.5713/ajas.2014.r.02

Kong, C., C.S. Park and B.G. Kim, 2015. Effects of an enzyme complex on in vitro dry matter digestibility of feed ingredients for pigs. SpringerPlus, 4: 261. DOI: $10.1186 / \mathrm{s} 40064-015-1060-1$

Le Goff, G. and J. Noblet, 2001. Comparative total tract digestibility of dietary energy and nutrients in growing pigs and adult sows. J. Anim. Sci., 79: 2418-2427. DOI: 10.2527/2001.7992418x

Navarro, D.M.D.L., E.M.A.M. Bruininx, L. de Jong and H.H. Stein, 2018. Analysis for low-molecularweight carbohydrates is needed to account for all energy-contributing nutrients in some feed ingredients, but physical characteristics do not predict in vitro digestibility of dry matter. J. Anim. Sci., 96: 532-544. DOI: 10.1093/jas/sky010

Noblet, J. and J. Van Milgen, 2004. Energy value of pig feeds: Effect of pig body weight and energy evaluation system. J. Anim. Sci., 82: E229-E238. DOI: $10.2527 / 2004.8213 \_$supplE229x

NRC, 2012. Nutrient requirements of swine. 11th rev. ed. Natl. Acad. Press, Washington, DC, USA.

Nursten, H., 2005. The Maillard Reaction. Chemistry, Biochemistry and Implications. Royal Society of Chemistry, Cambridge, UK.

Palacios, M.F., R.A. Easter, K.T. Soltwedel, C.M. Parsons and M.W. Douglas et al., 2004. Effect of soybean variety and processing on growth performance of young chicks and pigs. J. Anim. Sci., 82: 1108-1114. DOI: 10.2527/2004.8241108x

Park, C.S., S.I. Oh and B.G. Kim, 2013. Prediction of basal endogenous losses of amino acids based on body weight and feed intake in pigs fed nitrogenfree diets. Rev. Colomb. Cienc. Pecu., 26: 186-192.

Park, C.S., I. Park and B.G. Kim, 2016. Effects of an enzyme cocktail on digestible and metabolizable energy concentrations in barley, corn and wheat fed to growing pigs. Livest. Sci., 187: 1-5.

DOI: 10.1016/j.livsci.2016.02.003

Piao, M.Y., H.J. Kim, J.K. Seo, T.S. Park and J.S. Yoon et al., 2012. Effects of synchronization of carbohydrate and protein supply in total mixed ration with Korean rice wine residue on ruminal fermentation, nitrogen metabolism and microbial protein synthesis in Holstein steers. Asian-Australas. J. Anim. Sci., 25: 1568-1574.

DOI: 10.5713 ajas.2012.12379 
Rijal, T., D. Nepali, R. Sah and D. Sharma, 2009. Economic use of brewer's dried grain (BDG) in the diet of swine. Nepal J. Sci. Technol., 10: 29-35. DOI: 10.3126/njst.v10i0.2820

Sauvant, D., J.M. Perez and G. Tran, 2004. Tables of composition and nutritional value of feed materials: pigs, poultry, cattle, sheep, goats, rabbits, horses and fish. Wageningen Academic Publishers, the Netherlands and INRA Editions, Paris, France.

Son, A.R., Y. Hyun, J.K. Htoo and B.G. Kim, 2014. Amino acid digestibility in copra expellers and palm kernel expellers by growing pigs. Anim. Feed Sci. Technol., 187: 91-97, DOI: 10.1016/j.anifeedsci.2013.09.015

Son, A.R., C.S. Park and B.G. Kim, 2017. Determination and prediction of digestible and metabolizable energy concentrations in byproduct feed ingredients fed to growing pigs. Asian-Australas. J. Anim. Sci., 30: 546-553. DOI: 10.5713/ajas.16.0607

Stein, H.H., B. Seve, M.F. Fuller, P.J. Moughan and C.F.M. De Lange, 2007. Invited review: Amino acid bioavailability and digestibility in pig feed ingredients: Terminology and application. J. Anim. Sci., 85: 172-180. DOI: 10.2527/jas.2005-742
Stein, H.H., C.F. Shipley and R.A. Easter, 1998. A technique for inserting a T-cannula into the distal ileum of pregnant sows. J. Anim. Sci., 76: 1433-1436. DOI: $10.2527 / 1998.7651433 \mathrm{x}$

Sung, J.Y., S.Y. Ji, A.R. Son and B.G. Kim, 2019. Energy concentration and phosphorus digestibility in hatchery byproducts fed to nursery pigs. Animals, 9: 255. DOI:10.3390/ani9050255

Van Kempen, T.A.T.G., I.B. Kim, A.J.M. Jansman, M.W.A. Verstegen and J.D. Hancock et al., 2002. Regional and processor variation in the ileal digestible amino acid content of soybean meals measured in growing swine. J. Anim. Sci., 80: 429-439. DOI: 10.2527/2002.802429x

Van Soest, P.J., J.B. Robertson and B.A. Lewis, 1991. Methods for dietary fiber, neutral detergent fiber and nonstarch polysaccharides in relation to animal nutrition. J. Dairy Sci., 74: 3583-3597.

DOI: $10.3168 /$ jds.S0022-0302(91)78551-2 